\title{
Short-wavelength sensitive visual field loss in patients with clinically significant diabetic macular oedema
}

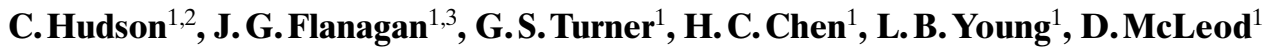 \\ ${ }^{1}$ University Department of Ophthalmology, Manchester Royal Eye Hospital, Manchester, UK \\ ${ }^{2}$ School of Biomedical Sciences, University of Ulster, Coleraine, County Londonderry, Northern Ireland \\ ${ }^{3}$ Department of Ophthalmology, University of Toronto, The Toronto Hospital, Toronto, Ontario, Canada
}

\begin{abstract}
Summary The aim of the study was to compare the sensitivity of short-wavelength and conventional automated static threshold perimetry for the psychophysical detection of abnormality in patients with clinically significant diabetic macular oedema. The sample comprised 24 patients with clinically significant diabetic macular oedema (mean age 59.75 years, range $45-75$ years). One eye of each patient was selected. Exclusion criteria included the presence of lenticular opacity. The sensitivity of the macular visual field of each patient was determined with programme 10-2 of the Humphrey Field Analyser on two occasions, using both short-wavelength and conventional stimulus parameters; the results of the second session were analysed to minimise learning effects. A pointwise horizontal hemifield asymmetry analysis was derived for short-wavelength perimetry (thereby negating the influence of pre-receptoral absorption); the pointwise pattern deviation probability plot was analysed for conventional perimetry. Abnormality was defined as 3 or more contiguous stimulus locations with negative asymmetries (short-wavelength) or reduced sensitivity values (conventional)
\end{abstract}

that resulted in a statistical probability level of $p$ less than 0.05 . The fields of 8 patients were abnormal as assessed by conventional perimetry while all were classified as abnormal using short-wavelength perimetry. In the 8 patients who exhibited both abnormal conventional and abnormal short-wavelength perimetry results, the extent of field loss was generally greater using short-wavelength perimetry. The position of the localised field loss (i.e. as distinct from field loss that was generalised across the visual field) assessed by short-wavelength perimetry corresponded with the clinical mapping of the area of diabetic macular oedema but the extent of this loss was generally greater than that suggested by clinical assessment. Short-wavelength automated perimetry offers improved sensitivity for the psychophysical detection of clinically significant diabetic macular oedema. [Diabetologia (1998) 41: 918-928]

Keywords Perimetry, Visual Field, Short-Wavelength Sensitivity, Selective Loss, Diabetic Macular Oedema.
Received: 5 January 1998 and in revised form: 13 March 1998

Corresponding author: C. Hudson, School of Biomedical Sciences, University of Ulster, Coleraine, County Londonderry, BT52 1SA, Northern Ireland

Abbreviations: SWS, Short-wavelength sensitive; DMO, diabetic macular oedema; $\log$ MAR, log minimum angle of resolution; CNS, central nervous system; LOCS, Lens Opacities Classification System; NC, nuclear colour; NO, nuclear opalescence; C, cortical cataract; $\mathrm{P}$, posterior sub-capsular cataract; HFA, Humphrey Field Analyser; SWAP, short-wavelength automated perimetry; $\mathrm{dB}$, decibel; asb, apostilb
Perimetry comprises the assessment of visual sensitivity of retinal locations eccentric from the fovea. Short-wavelength automated perimetry employs a blue stimulus in order to preferentially stimulate the short-wavelength sensitive (SWS) pathway and a high luminance yellow background to saturate both the medium- and long-wavelength sensitive pathways and to simultaneously suppress rod activity [1]. Numerous studies have shown that short-wavelength perimetry detects glaucomatous visual field damage at an earlier stage in the disease process than conventional white-on-white perimetry [2-11]. 
A selective loss of SWS pathway sensitivity (i.e. in the absence of achromatic sensitivity loss) has been demonstrated in diabetic patients with minimal or no retinopathy using laboratory based paradigms and foveal stimuli [12-19]. SWS pathway sensitivity loss has been: (i) shown to be comparatively greater in diabetic patients than in glaucomatous patients (i.e. the reduction of achromatic sensitivity is minimal in diabetics) $[16,20]$ and; (ii) suggested to reflect the magnitude of diabetic macular oedema (DMO) $[14,18]$.

The psychophysical detection of early visual dysfunction in the diabetic eye may predict the development of sight-threatening retinopathy. However, few clinical studies have investigated the potential of short-wavelength perimetry for this purpose or for the assessment of the severity of diabetic retinopathy. Lutze and Bresnick [21] compared short-wavelength perimetry with conventional perimetry in a group of diabetic patients with varying degrees of retinopathy. The study failed to find a selective loss of short-wavelength sensitivity within the central $30^{\circ}$ visual field but focal defects were found for both perimetry conditions that significantly correlated with the overall level of retinopathy. In addition, the absorption [22-23] and scatter [24] of short-wavelength light by the ocular media, and particularly the absorption of short-wavelength light by the macular pigment [25-26], has until now confounded the interpretation of short-wavelength perimetric thresholds within the macular region. The net effect of the pre-receptoral "filters" is to produce a symmetrical reduction of SWS pathway sensitivity across the visual field. Consequently, analytical methodologies have been recommended that negate the attenuation of SWS pathway sensitivity by the ocular media [27] and by the macular pigment [26]. Furthermore, asymmetry analysis has been demonstrated to improve both the sensitivity and the specificity of short-wavelength automated perimetry in the detection of glaucomatous visual field loss when compared with analysis based upon absolute sensitivity [27].

The aim of this study was to compare the sensitivity of short-wavelength with conventional automated static threshold perimetry in the detection of psychophysical abnormality in a cohort of patients with clinically significant DMO. The influence of the pre-receptoral filters on short-wavelength perimetry was negated using a pointwise horizontal and vertical hemifield asymmetry analysis, i.e. the analysis was sensitive to variation in the shape of the "hill of vision" relative to that of a normal database rather than being dependent upon absolute sensitivity (as was also the case with conventional perimetry).

\section{Subjects and methods}

Sample. The sample comprised 24 patients (18 men and 6 women) with clinically significant DMO as defined by the Early Treatment Diabetic Retinopathy Study criteria [28] which study's definition of clinically significant DMO includes any one, or a combination, of the following: (i) retinal thickening involving or within $500 \mu \mathrm{m}$ of the centre of the macula; (ii) hard exudate(s) at or within $500 \mu \mathrm{m}$ of the centre of the macula, if associated with thickening of the adjacent retina (but not residual hard exudates remaining after disappearance of retinal thickening); (iii) a zone or zones of retinal thickening one disc area or larger in size, any part of which is within 1 disc diameter of the centre of the macula. The mean age of the sample patients was 59.75 years (range $45-75$ years). The mean time from diagnosis of diabetes was 8.5 years (range $2-18$ years); 3 patients were insulin-dependent and 21 patients were non-insulin dependent and receiving oral hypoglycaemic medication. One eye was randomly assigned to the study if both eyes exhibited clinically significant DMO; 11 right eyes and 13 left eyes were assessed. The demographic details are shown in Table 1. A conservative standardised effect size of 1.0 was used for the sample size estimation (i.e. the standard deviation of sensitivity using short-wavelength perimetry was assumed to be equal to the expected effect size). Using a two-tailed alpha of 0.05 and a beta of 0.10 (i.e. power $=90 \%$ ), then the minimum sample size for the diabetic patient group should be 21 .

Two medical retina specialists independently confirmed the diagnosis of clinically significant DMO before inclusion of the patient in the study. Inclusion criteria for the diabetic patients included a visual acuity (i.e. log minimum angle of resolution, $\log$ MAR) of 0.25 or better using the $96 \%$ contrast Regan chart (i.e. Snellen equivalent visual acuity of $6 / 9$ to $6 / 12$ ). Exclusion criteria comprised: (i) a distance refractive error greater than \pm 6.00 dioptres sphere or \pm 1.50 dioptres cylinder or both; (ii) a family history of glaucoma in a first degree relative; (iii) an intra-ocular pressure $22 \mathrm{mmHg}$ or more; (iv) any other eye disease or disorder (including lenticular opacity - see below); (v) any previous laser photocoagulation treatment; (vi) proliferative diabetic retinopathy and its sequelae, e.g. vitreous haemorrhage and retinal detachment; (vii) central nervous system (CNS) disorders or psychiatric illness and; (viii) systemic medication with known CNS effects, e.g. tranquillisers. Lenticular opacity was graded on the basis of slit lamp appearance and the Lens Opacities Classification System (LOCS) III [29]. Eyes with the following LOCS III grades were excluded from the study: (i) nuclear colour greater than NC2; (ii) nuclear opalescence greater than NO2; (iii) cortical cataract greater than $\mathrm{C} 2$ and; (iv) posterior sub-capsular cataract P1 or more.

The respective perimetry results from the patients were compared with databases of normal fields. Normative data was modelled for each stimulus location to reflect the influence of age on sensitivity (and on the range of sensitivity values) across a group of normal subjects. The pointwise perimetric sensitivity of the patient was then directly compared to normative data of the appropriate age. For conventional perimetry, the established Statpac II normal database [30] of Humphrey Field Analyser (HFA, Humphrey Instruments Inc., San Leandro, Calif., USA) programme 10-2 was used. For shortwavelength automated perimetry (SWAP), normal HFA programme 10-2 sensitivity values were derived from the results of 400 normal subjects between the ages of 18 and 84 years (mean age 48 years, SD 17 years) who had undergone shortwavelength automated perimetry (SWAP) using programme 30-2 i.e. the HFA Statpac for SWAP database. Of the subjects 230 were aged $18-50$ years, 90 were aged 51-65 years and 80 were aged 66-84 years. Normal subjects were recruited at vari- 
Table 1. Demographic details for the diabetic patients (Px, patient number; Dur., duration of diabetes; Haem., haemoglobin; VA, $\log$ MAR visual acuity at $100 \mathrm{cdm}^{-2}$; SW, short-wavelength automated perimetry; RE, right eye; LE, left eye)

\begin{tabular}{|c|c|c|c|c|c|c|c|c|}
\hline $\mathrm{Px}$ & $\begin{array}{l}\text { Age } \\
\text { (yrs) }\end{array}$ & $\begin{array}{l}\text { Dur. } \\
\text { (yrs) }\end{array}$ & $\begin{array}{l}\text { Diabetes } \\
\text { Type }\end{array}$ & $\begin{array}{l}\text { Haer } \\
(\%)\end{array}$ & $\begin{array}{l}\text { Glucose } \\
(\mathrm{mmol} / \mathrm{l})\end{array}$ & Eye & VA & $\begin{array}{l}\text { SW order } \\
\text { (at Visit 2) }\end{array}$ \\
\hline 1 & 59 & 6 & I & 6.6 & 7.7 & $\mathrm{LE}$ & 0.1 & 2nd \\
\hline 2 & 63 & 5 & II & 8.2 & 17.4 & $\mathrm{RE}$ & 0.2 & $1 \mathrm{st}$ \\
\hline 3 & 58 & 18 & II & 7.6 & 12.3 & $\mathrm{RE}$ & 0.2 & $1 \mathrm{st}$ \\
\hline 4 & 59 & 2 & II & 8.6 & 5.6 & LE & 0.0 & 2nd \\
\hline 5 & 61 & 10 & II & 10.5 & 16.5 & $\mathrm{LE}$ & 0.25 & $1 \mathrm{st}$ \\
\hline 6 & 61 & 8 & II & 7.3 & 8.4 & $\mathrm{LE}$ & 0.25 & $1 \mathrm{st}$ \\
\hline 7 & 66 & 3 & II & 7.6 & 10.2 & LE & 0.1 & $1 \mathrm{st}$ \\
\hline 8 & 58 & 10 & II & 7.7 & 11.0 & $\mathrm{RE}$ & 0.2 & $1 \mathrm{st}$ \\
\hline 9 & 71 & 5 & II & 5.4 & 8.4 & $\mathrm{RE}$ & 0.0 & $2 \mathrm{nd}$ \\
\hline 10 & 52 & 7 & II & 12.2 & 19.3 & RE & 0.0 & $1 \mathrm{st}$ \\
\hline 11 & 47 & 11 & I & N/A & 19.9 & $\mathrm{RE}$ & 0.0 & $1 \mathrm{st}$ \\
\hline 12 & 70 & 16 & II & 9.1 & 12.3 & LE & 0.2 & $1 \mathrm{st}$ \\
\hline 13 & 55 & 3 & II & 9.6 & 11.3 & RE & 0.25 & $1 \mathrm{st}$ \\
\hline 14 & 61 & 7 & II & 9.3 & 8.0 & LE & 0.1 & 2nd \\
\hline 15 & 59 & 3 & II & 9.2 & 9.5 & LE & 0.1 & 2nd \\
\hline 16 & 66 & 17 & II & 12.9 & 17.8 & RE & 0.0 & 2nd \\
\hline 17 & 75 & 15 & II & 7.7 & 11.9 & $\mathrm{LE}$ & 0.0 & $1 \mathrm{st}$ \\
\hline 18 & 58 & 12 & I & 7.9 & 20.5 & LE & 0.0 & $1 \mathrm{st}$ \\
\hline 19 & 64 & 7 & II & 7.2 & 4.0 & $\mathrm{LE}$ & 0.0 & $1 \mathrm{st}$ \\
\hline 20 & 60 & 15 & II & 5.5 & 6.9 & $\mathrm{RE}$ & 0.2 & $1 \mathrm{st}$ \\
\hline 21 & 45 & 10 & II & 6.3 & 3.9 & $\mathrm{RE}$ & 0.0 & $2 \mathrm{nd}$ \\
\hline 22 & 50 & 7 & II & 7.3 & 13.5 & $\mathrm{RE}$ & 0.1 & $1 \mathrm{st}$ \\
\hline 23 & 45 & 3 & II & 8.7 & 12.3 & $\mathrm{LE}$ & 0.25 & $2 \mathrm{nd}$ \\
\hline 24 & 71 & 5 & II & 8.4 & 19.7 & $\mathrm{LE}$ & 0.0 & $2 \mathrm{nd}$ \\
\hline
\end{tabular}

ous international centres for the HFA Statpac II and the Statpac for SWAP databases using equivalent inclusion and exclusion criteria to those used for the diabetic patients in this study.

Procedures. Perimetry was undertaken using the HFA 640, an automated static threshold projection perimeter. Static stimuli were presented for a duration of $200 \mathrm{~ms}$ onto a cupola of $33 \mathrm{~cm}$ radius. The standard, full threshold strategy was used throughout the study; the thresholding strategy used a double staircase algorithm in which threshold was initially crossed using a 4 decibel (dB) step size and was then crossed in the opposite direction using a $2 \mathrm{~dB}$ step size. The last seen stimulus was taken as threshold at each location. The initial stimulus was presented at an intensity slightly brighter than the patient's expected age-matched threshold [31].

For conventional perimetry, the HFA 640 used a bowl illumination of $10 \mathrm{cdm}^{-2}$ and a Goldmann equivalent size III (angular subtense $0.431^{\circ}$ ) default static stimulus. The bowl illumination and stimulus were produced using polychromatic light sources. The sensitivity scale was referenced to a maximum stimulus luminance of 10,000 apostilbs (asb). For short-wavelength perimetry, the HFA used a yellow (Schott OG530 filter) bowl illumination of $100 \mathrm{cdm}^{-2}$ and a $440 \mathrm{~nm}$ narrow-band (27 $\mathrm{nm}$ half power bandwidth) blue stimulus [32]. The default static stimulus for short-wavelength perimetry was a Goldmann equivalent size $\mathrm{V}$ (angular subtense $1.724^{\circ}$ ). The sensitivity scale was referenced to a maximum stimulus luminance of 64.56 asb. These parameters have been shown to provide approximately $1 \log$ unit of SWS pathway isolation [32]; the relatively narrow-band characteristics of the $440 \mathrm{~nm}$ stimulus filter ensured that chromatic aberration did not result in stimulation of the medium-wavelength sensitive pathway.

Programme 10-2 of the HFA 640 was used and comprised 69 stimulus locations within $10^{\circ}$ eccentricity of the fovea (including foveal threshold). The distance refractive correction of the study eye, together with the appropriate near addition for the patient's age, was used to correct for a viewing distance of $33 \mathrm{~cm}$. The refraction was checked prior to each perimetry session to compensate for any transient refractive changes associated with diabetes [33]. Perimetry was undertaken on two separate occasions using conventional and short-wavelength perimetry parameters; the mean interval between the two visits was 12 days (range 1 to 31 days). Mandatory rest periods were given at least every 5 min during each perimetry session to minimise the influence of fatigue [34]. The order of stimulus condition (i.e. conventional or short-wavelength) at visit 1 was varied between patients and was then systematically varied between visits (i. e. short-wavelength was undertaken first at visit 1 and second at visit 2). For visit 2, 15 diabetic patients underwent short-wavelength perimetry first and 9 patients underwent conventional perimetry first. The results of the second perimetry session were analysed to minimise the influence of learning [35]. The group mean times to complete each stimulus condition as a function of order for visit 2 were: conventional first $(n=9), 12 \mathrm{~min} 30 \mathrm{~s}$ (SD $45 \mathrm{~s}$ ); conventional second $(n=15), 12 \mathrm{~min}$ (SD $45 \mathrm{~s})$; short-wavelength first, $15 \mathrm{~min}$ (SD $1 \mathrm{~min} 47 \mathrm{~s}$ ); and short-wavelength second, 15 min $47 \mathrm{~s}$ (SD $2 \min 13 \mathrm{~s})$.

The two medical retina specialists mapped the extent of DMO onto a clear acetate sheet which detailed the retinal vascular pattern of each eye as derived from a $20^{\circ} \times 20^{\circ}$ scanning laser tomography image. The extent of DMO was assessed using contact, or Volk, lens fundus biomicroscopy Volk, Ohio, USA. This image (acquired at visit 1) and the mapping of the extent of DMO (visit 2) were both undertaken following perimetry. Each medical retina specialist was blind to the perimetry results and to each other's assessment of the extent of DMO. The level of agreement of the mapping of the extent of DMO between the medical retina specialists (i.e. any two from GST, HCC, or LBY) was high (in terms of the allocation of retinal thickening on a quadrant-wise basis). The medical retina specialists disagreed on the extent of DMO in only 2 pa- 


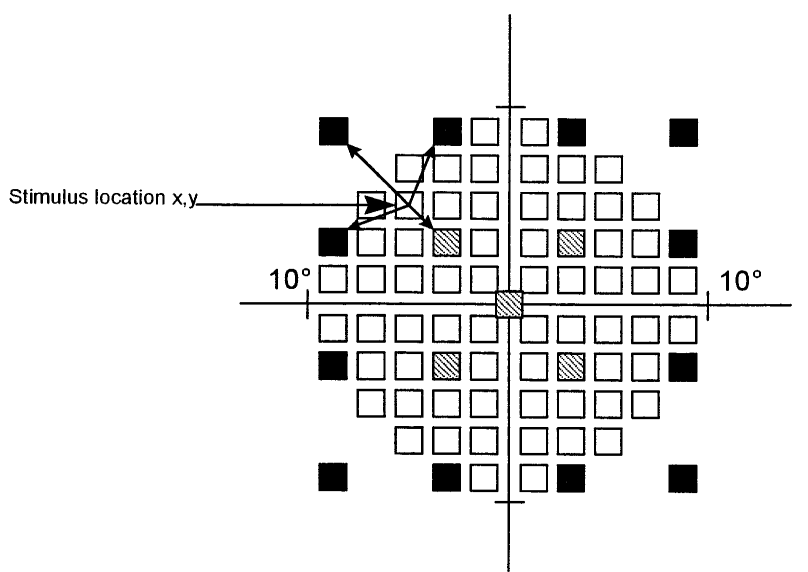

Fig. 1. Stimulus locations of HFA programme 10-2. The filled squares (i.e. $\square$ and $\mathbb{Q}$ ) show the stimulus locations of HFA programme 30-2 that were used to interpolate normal shortwavelength sensitivity values for programme 10-2 ( $\square$ represent 30-2 stimulus locations which do not coincide with 10-2 locations, while $\mathbb{N}$ represent coincident stimulus locations). Stimulus location $x, y$ and the four surrounding HFA 30-2 stimulus locations are indicated by the arrows

tients (i.e. no. 4 , no. 9); in each of these patients, agreement was reached for 1 or 2 quadrants but disagreement occurred on the presence of DMO in another quadrant. In these 2 patients, the extent of DMO was allocated to every indicated quadrant whether, or not, agreement was reached between the two medical retina specialists.

Analysis. Fields that resulted in a false-positive or false-negative response rate greater than $33 \%$, and those that exhibited fixation losses greater than $20 \%$ (i.e. Heijl-Krakau technique [36]), were excluded from the analysis.

For conventional perimetry, the pattern deviation plot of the HFA Statpac II database was used to illustrate the pointwise deviation of the shape of the visual field from the agematched normal field [37]. This was achieved by correcting for generalised shifts in the overall sensitivity which consequently emphasised localised sensitivity loss (i.e. as distinct from field loss that was generalised across the visual field). Those points that had the highest measured sensitivities were assumed to be unaffected by localised visual field loss. The general sensitivity level for the pattern deviation plot was calculated from the stimulus location with the seventh highest sensitivity [38]. For this study, abnormality was defined as three or more contiguous stimulus locations of the pattern deviation plot with statistical probability levels of $p$ less than 0.05 . The total deviation probability plots are also presented in the figures.

For short-wavelength perimetry, a pointwise hemifield asymmetry analysis was established. Using this analytical approach, the influence of pre-receptoral absorption $[22,23,25$, 26] and light scatter [24] was negated since the overall effect of these factors results in a symmetrical attenuation of the "hill of vision". In addition, this analysis can be expected to avoid the artifactual assigning of abnormality in patients with high ocular media absorption and the problems associated with the limited measurement range of short-wavelength perimetry; this is of particular relevance in diabetic patients who are known to exhibit exaggerated ocular media absorption values [39]. A weighted linear interpolation procedure, based upon the angular distance between the 10-2 stimulus location to be derived and the four surrounding 30-2 locations, was used (Fig.1). Consider stimulus location x,y of programme 10-2; the nearest supero-temporal stimulus location (right eye) of programme $30-2$ is $4.5^{\circ}$, the nearest supero-nasal location is $5.6^{\circ}$, the nearest infero-nasal location is $4.5^{\circ}$ and the nearest infero-temporal location is $2.8^{\circ}$. For each decade, the interpolated sensitivity $(\mathrm{dB})$ of stimulus location $\mathrm{x}, \mathrm{y}$ of programme $10-2$ is given by:

$$
\begin{aligned}
\mathrm{dB}_{\mathrm{x}, \mathrm{y}}= & {\left[\left(\mathrm{dB}_{\mathrm{ST}} \times 17.5 / 4.5\right)+\left(\mathrm{dB}_{\mathrm{SN}} \times 17.5 / 5.6\right)+\right.} \\
& \left.\left(\mathrm{dB}_{\mathrm{IN}} \times 17.5 / 4.5\right)+\left(\mathrm{dB}_{\mathrm{IT}} \times 17.5 / 2.8\right)\right] / 17.15
\end{aligned}
$$

where $\mathrm{dB}_{\mathrm{ST}}, \mathrm{dB}_{\mathrm{SN}}, \mathrm{dB}_{\mathrm{IN}}$ and $\mathrm{dB}_{\mathrm{IT}}$ represent age-matched normal data of the nearest supero-temporal, supero-nasal, inferonasal and infero-temporal programme 30-2 stimulus locations respectively.

The pointwise difference of programme 10-2 short-wavelength interpolated sensitivity between corresponding stimulus locations in the opposite horizontal hemifield was calculated; the group mean of differences and the standard deviation of the differences were used to establish confidence limits for the asymmetry of pointwise horizontal hemifield sensitivity values. For this study, abnormality was defined as three or more contiguous stimulus locations of the pointwise horizontal hemifield asymmetry plot with statistical probability levels of $p$ less than 0.05 . A pointwise vertical hemifield asymmetry analysis was also undertaken in order to show the full extent of any localised field loss, i. e. if the localised field loss was evenly distributed across the horizontal midline and located in one hemifield, the full extent of the defect may be underestimated (assuming an equal magnitude of sensitivity loss on either side of the midline) using solely the horizontal hemifield asymmetry analysis.

The extent of any localised sensitivity loss was approximated for both perimetry conditions by determining whether or not field loss had occurred within each of the four quadrants. For a given quadrant to be assigned as containing a localised field loss, three contiguous stimulus locations with statistical probability levels of $p$ less than 0.05 had to lie within the quadrant. For conventional perimetry, the pointwise pattern deviation plot was used to determine the extent of the localised sensitivity loss while for short-wavelength perimetry the pointwise horizontal and the vertical hemifield asymmetry plots were both evaluated.

\section{Results}

A detailed summary of the results is given in Table 2. One patient was excluded from the analysis owing to a false-positive response rate greater than $33 \%$. Examples of representative conventional and shortwavelength perimetry pointwise probability plots are given in Figures 2 to 6.

No diabetic patient exhibited normal results for both perimetry conditions. The fields of 8 patients were abnormal as assessed by conventional perimetry, whilst all 23 fields were classified as abnormal using short-wavelength perimetry (Table 2). In the 8 diabetic patients exhibiting both abnormal conventional and abnormal short-wavelength perimetry results, the position of the localised field loss corresponded using the two perimetry conditions (Table 2). Howev- 
Table 2. Results summary table showing the position (by quadrant) of retinal thickening and the position of localised sensitivity loss for conventional and short-wavelength, automated perimetry (A, abnormal; $\mathrm{N}$, normal; ${ }^{1}$, foveal involvement; SN, supero-nasal; ST, supero-temporal; IT, infero-temporal; IN, infero-nasal). For a given quadrant to be assigned as containing a localised field loss (i. e. X), three contiguous stimulus locations with statistical probability levels of $p<0.05$ had to lie within the quadrant. Note: localised oedema in the inferior temporal quadrant of the retina will result in a superior nasal visual field defect after projection through the nodal point of the eye

\begin{tabular}{|c|c|c|c|c|c|c|c|c|c|c|c|c|c|c|}
\hline \multirow[t]{3}{*}{$\mathrm{Px}$} & \multicolumn{4}{|c|}{$\begin{array}{l}\text { Clinical assessment of DMO } \\
\text { Location of thickening: }\end{array}$} & \multicolumn{5}{|c|}{$\begin{array}{l}\text { Conventional perimetry } \\
\text { Position of localised field loss: }\end{array}$} & \multicolumn{5}{|c|}{$\begin{array}{l}\text { Short-wavelength perimetry } \\
\text { Position of localised field loss: }\end{array}$} \\
\hline & \multicolumn{2}{|c|}{ Quadrant: } & \multirow[b]{2}{*}{ IT } & \multirow[b]{2}{*}{ IN } & \multirow[t]{2}{*}{$\mathrm{A} / \mathrm{N}$} & \multicolumn{2}{|c|}{ Quadrant: } & \multirow[b]{2}{*}{ SN } & \multirow[b]{2}{*}{ ST } & \multirow[t]{2}{*}{$\mathrm{A} / \mathrm{N}$} & \multicolumn{2}{|c|}{ Quadrant: } & \multirow[b]{2}{*}{$\mathrm{SN}$} & \multirow[b]{2}{*}{ ST } \\
\hline & SN & ST & & & & IT & IN & & & & IT & IN & & \\
\hline 1 & $\mathrm{X}^{1}$ & & & & $\mathbf{A}$ & $\mathrm{X}$ & & & & $\mathbf{A}$ & $\mathrm{X}$ & & $\mathrm{X}$ & \\
\hline 2 & & $\mathrm{X}$ & $\mathrm{X}$ & & $\mathrm{N}$ & & & & & A & & $\mathrm{X}$ & $\mathrm{X}$ & $\mathrm{X}$ \\
\hline 3 & & $\mathrm{X}$ & $\mathrm{X}$ & & $\mathbf{A}$ & & $\mathrm{X}$ & $\mathrm{X}$ & & $\mathbf{A}$ & & $\mathrm{X}$ & $\mathrm{X}$ & $\mathrm{X}$ \\
\hline 4 & & $\mathrm{X}$ & $\mathrm{X}$ & & $\mathbf{A}$ & & $\mathrm{X}$ & $\mathrm{X}$ & & A & & $\mathrm{X}$ & $\mathrm{X}$ & $\mathrm{X}$ \\
\hline 5 & $\mathrm{X}$ & & & $\mathrm{X}$ & $\mathrm{N}$ & & & & & $\mathbf{A}$ & & $\mathrm{X}$ & $\mathrm{X}$ & $\mathrm{X}$ \\
\hline 6 & $\mathrm{X}$ & $\mathrm{X}$ & $\mathrm{X}$ & & A & & & & $\mathrm{X}$ & $\mathbf{A}$ & & $\mathrm{X}$ & $\mathrm{X}$ & $\mathrm{X}$ \\
\hline 7 & & $\mathrm{X}$ & & & $\mathrm{N}$ & & & & & $\mathbf{A}$ & $\mathrm{X}$ & $\mathrm{X}$ & & $\mathrm{X}$ \\
\hline 8 & & & $\mathrm{X}^{1}$ & $\mathrm{X}^{1}$ & A & & & & $\mathrm{X}$ & $\mathbf{A}$ & & & $\mathrm{X}$ & $\mathrm{X}$ \\
\hline 9 & $\mathrm{X}$ & & $\mathrm{X}$ & $\mathrm{X}$ & $\mathrm{N}$ & & & & & $\mathbf{A}$ & $\mathrm{X}$ & $\mathrm{X}$ & & $\mathrm{X}$ \\
\hline 10 & & $\mathrm{X}$ & & & $\mathrm{N}$ & & & & & $\mathbf{A}$ & & $\mathrm{X}$ & & \\
\hline 11 & & $\mathrm{X}^{1}$ & & & $\mathbf{A}$ & & $\mathrm{X}$ & & & $\mathbf{A}$ & & $\mathrm{X}$ & $\mathrm{x}$ & \\
\hline 12 & & & $\mathrm{X}^{1}$ & $\mathrm{X}^{1}$ & $\mathbf{A}$ & & & $\mathrm{X}$ & $\mathrm{X}$ & $\mathbf{A}$ & & & $\mathrm{X}$ & $\mathrm{X}$ \\
\hline 13 & & & $\mathrm{X}^{1}$ & $\mathrm{X}^{1}$ & $\mathrm{~N}$ & & & & & $\mathbf{A}$ & $\mathrm{X}$ & $\mathrm{X}$ & $\mathrm{X}$ & $\mathrm{X}$ \\
\hline 14 & $\mathrm{X}$ & & & & - & & & & & - & & & & \\
\hline 15 & & & $\mathrm{X}$ & & $\mathbf{A}$ & & & $\mathrm{X}$ & & $\mathbf{A}$ & & $\mathrm{X}$ & $\mathrm{X}$ & $\mathrm{X}$ \\
\hline 16 & $\mathrm{X}^{1}$ & & & $\mathrm{X}^{1}$ & $\mathrm{~N}$ & & & & & $\mathbf{A}$ & & $\mathrm{X}$ & $\mathrm{X}$ & $\mathrm{X}$ \\
\hline 17 & & $\mathrm{X}$ & $\mathrm{X}$ & & $\mathrm{N}$ & & & & & $\mathbf{A}$ & $\mathrm{X}$ & & $\mathrm{X}$ & $\mathrm{X}$ \\
\hline 18 & $\mathrm{X}^{1}$ & $\mathrm{X}^{1}$ & $\mathrm{X}^{1}$ & $\mathrm{X}^{1}$ & $\mathrm{~N}$ & & & & & $\mathbf{A}$ & $\mathrm{X}$ & & $\mathrm{X}$ & \\
\hline 19 & $\mathrm{X}$ & $\mathrm{X}$ & $\mathrm{X}$ & & $\mathrm{N}$ & & & & & $\mathbf{A}$ & & & $\mathrm{X}$ & \\
\hline 20 & $\mathrm{X}$ & $\mathrm{X}$ & & & $\mathrm{N}$ & & & & & $\mathbf{A}$ & $\mathrm{X}$ & & $\mathrm{X}$ & \\
\hline 21 & $\mathrm{X}$ & $\mathrm{X}$ & & $\mathrm{X}$ & $\mathrm{N}$ & & & & & A & $\mathrm{X}$ & & & \\
\hline 22 & $\mathrm{X}$ & $\mathrm{X}$ & & & $\mathrm{N}$ & & & & & $\mathbf{A}$ & $X$ & $\mathrm{X}$ & & \\
\hline 23 & & $\mathrm{X}$ & & & $\mathrm{N}$ & & & & & $\mathbf{A}$ & & $\mathrm{X}$ & & \\
\hline 24 & $\mathrm{X}$ & $\mathrm{X}$ & $\mathrm{X}$ & & $\mathrm{N}$ & & & & & $\mathbf{A}$ & & $\mathrm{X}$ & $\mathrm{X}$ & $\mathrm{X}$ \\
\hline
\end{tabular}

er, the extent of the localised field loss was generally greater (i.e. in 7 of the 8 patients) using short-wavelength perimetry (Figs. 5, 6). In the 15 patients who only exhibited abnormality using short-wavelength perimetry, the results of conventional perimetry were "teetering" in four cases i.e. two contiguous stimulus locations showed abnormality (or a number of non-contiguous stimulus locations showed abnormality) in the same quadrant(s) as the short-wavelength localised field loss (Fig. 4).

The position of the localised field loss assessed both by conventional and short-wavelength perimetry generally corresponded to the clinical mapping of the extent of DMO (Table 2). The extent of the localised sensitivity loss, however, was greater for short-wavelength perimetry than that suggested by clinical assessment in 11 of the 23 diabetic patients; the area was approximately of equal extent in 9 patients and was less than that suggested by clinical assessment in the 3 remaining patients. As expected, analysis of both the pointwise horizontal and the pointwise vertical hemifield asymmetry plots resulted in a greater extent of localised SWS pathway sensitivity loss for 18 of the diabetic patients than if only the pointwise horizontal hemifield asymmetry plot had been analysed.

\section{Discussion}

DMO is the largest single cause of visual impairment and legal blindness in diabetic patients [40-41]. Prompt laser photocoagulation of clinically significant (i.e. sight-threatening) DMO will stabilise vision in approximately $60 \%$ of eyes [42-45]. However, the clinical assessment of macular oedema, using contact lens or Volk lens fundus biomicroscopy, relies upon the subjective recognition of retinal thickening [46-47]. The differentiation of thickened retina from normal between-subject variation is difficult [48] and the detection of change in retinal thickening over time is problematic. Alternative means of detecting and monitoring DMO are necessary to improve the clinical management of this sight threatening complication of diabetes and for the evaluation of therapeutic protocols [49].

The pointwise hemifield asymmetry analysis of short-wavelength perimetry could represent a useful clinical tool for the psychophysical detection of DMO; it was conceived to negate the pre-receptoral attenuation of the blue stimulus by the ocular media and macular pigment and to avoid the problems associated with the limited measurement range of short- 

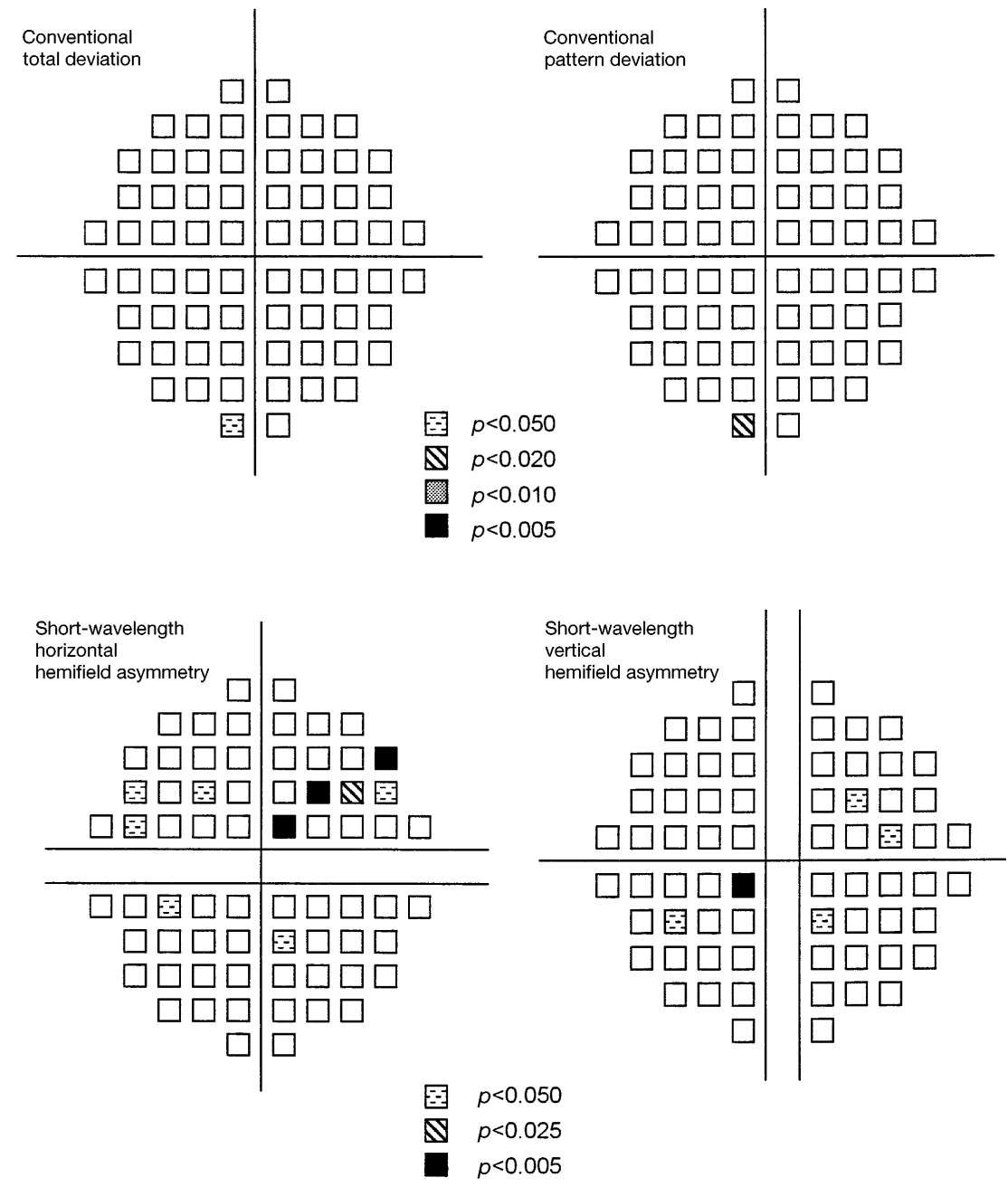

Fig. 2. Automated perimetry pointwise probability plots for diabetic patient no. 19 (Left eye, visit 2, short-wavelength perimetry undertaken after conventional perimetry). Top left; Total deviation plot of conventional perimetry. Top right; Pattern deviation plot of conventional perimetry. Bottom left; Horizontal hemifield asymmetry plot of short-wavelength perimetry. Bottom right; Vertical hemifield asymmetry plot of short-wavelength perimetry

wavelength perimetry. Alternative methods have been proposed for the analysis of short-wavelength perimetry in the glaucomatous eye [10]. Experience has shown, though, that total deviation and pattern deviation analyses frequently lack sufficient measurement range especially in patients who exhibit high ocular media absorption values. There is, however, a need to assess the specificity of the pointwise hemifield asymmetry analysis of short-wavelength perimetry, both in normal subjects and in diabetic patients with no DMO, prior to its use in a clinical setting. In addition, it has been suggested that some oral hypoglycaemics affect colour vision [50]; however, the precise nature of the suggested colour vision loss and the methodology used to show this acquired defect are vague. It is not unreasonable to assume, however, that any acquired colour vision loss resulting from oral hypoglycaemics would result in a diffuse loss of colour perception. The analysis used in this study for short-wavelength automated perimetry identified localised short-wavelength visual field defects rather than a symmetrical reduction of shortwavelength visual sensitivity. Conversely, Lutze and Bresnick [21] failed to find a selective loss of sensitivity using short-wavelength perimetry, in conjunction with HFA programme $30-2\left(6^{\circ}\right.$ square grid interstimulus spacing), in a group of diabetic patients with varying degrees of retinopathy (i.e. ranging from no retinopathy to proliferative retinopathy). The results reported in this paper were attained, however, from a cohort of patients with clinically significant DMO who had undergone HFA programme 10-2 ( $2^{\circ}$ square grid inter-stimulus spacing).

Although different forms of analysis have been used in this study to define abnormality for conventional and short-wavelength perimetry both were referenced to that of an age-matched normal database and were designed to elucidate deviation of the shape of the visual field from that of the normal eye. It is therefore argued that the analyses were equivalent 

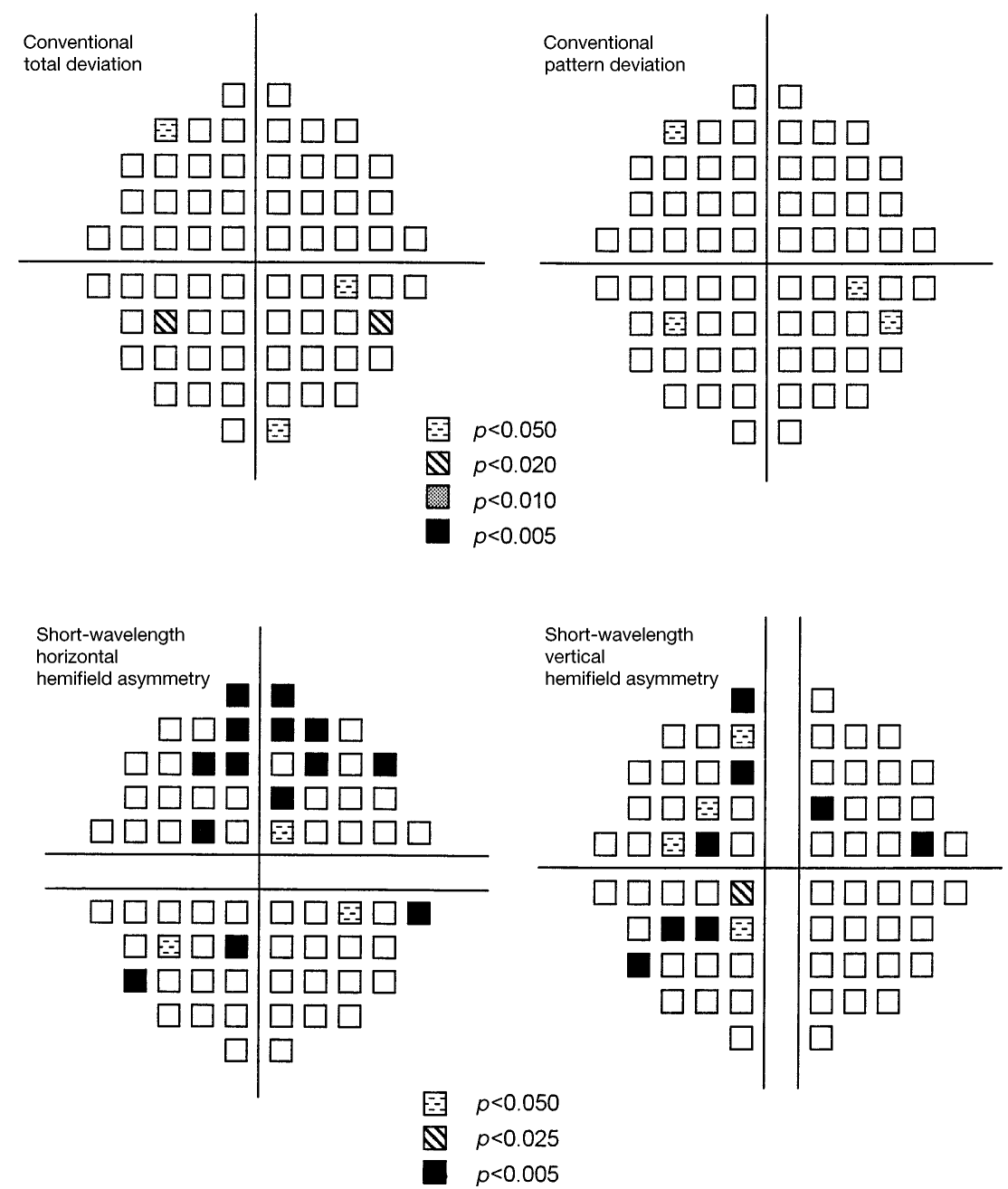

Fig.3. Automated perimetry pointwise probability plots for diabetic patient no. 2 (Right eye, visit 2, short-wavelength perimetry undertaken before conventional perimetry). Top left; Total deviation plot of conventional perimetry. Top right; Pattern deviation plot of conventional perimetry. Bottom left; Horizontal hemifield asymmetry plot of short-wavelength perimetry. Bottom right; Vertical hemifield asymmetry plot of short-wavelength perimetry

although the precise methodology (i.e. pattern deviation compared with pointwise hemifield asymmetry analysis) differed. The necessity to use different analyses for conventional and for short-wavelength perimetry was dictated by the preferential attenuation of the blue stimulus by the ocular media and macular pigment. A pointwise hemifield asymmetry analysis could also have been used for conventional perimetry but this would have entailed discarding the "gold standard" methodology of the pattern deviation probability plot. In addition, the pattern deviation probability plot used for the analysis of conventional perimetry assumed that those points with the highest sensitivities are unaffected by localised visual field loss; examination of the total deviation probability plots confirmed the validity of this assumption since no patient exhibited a generalised depression of visual field sensitivity.

The use of three or more contiguous stimulus locations with statistical probability levels of $p$ less than 0.05 to define abnormality is similar to criteria used previously [38]. More importantly, the same criteria (i.e. three or more contiguous stimulus locations with statistical probability levels of $p$ less than 0.05 ) were used for the analysis of conventional and of short-wavelength perimetry; however, abnormality as thus defined can occur in normal subjects (i.e. a false-positive assignment of abnormality) [51]. The fact that some of the diabetic patients exhibited abnormal short-wavelength fields and "teetering" conventional fields suggests that SWS pathway sensitivity loss precedes achromatic sensitivity loss (i.e. loss assessed using conventional perimetry).

The analysis of the extent of localised sensitivity loss was not equivalent between the two perimetry conditions. The pointwise pattern deviation plot was analysed for conventional perimetry while for short-wavelength perimetry both the pointwise horizontal and the pointwise vertical hemifield asymmetry plots were evaluated. Analysis of only the hori- 

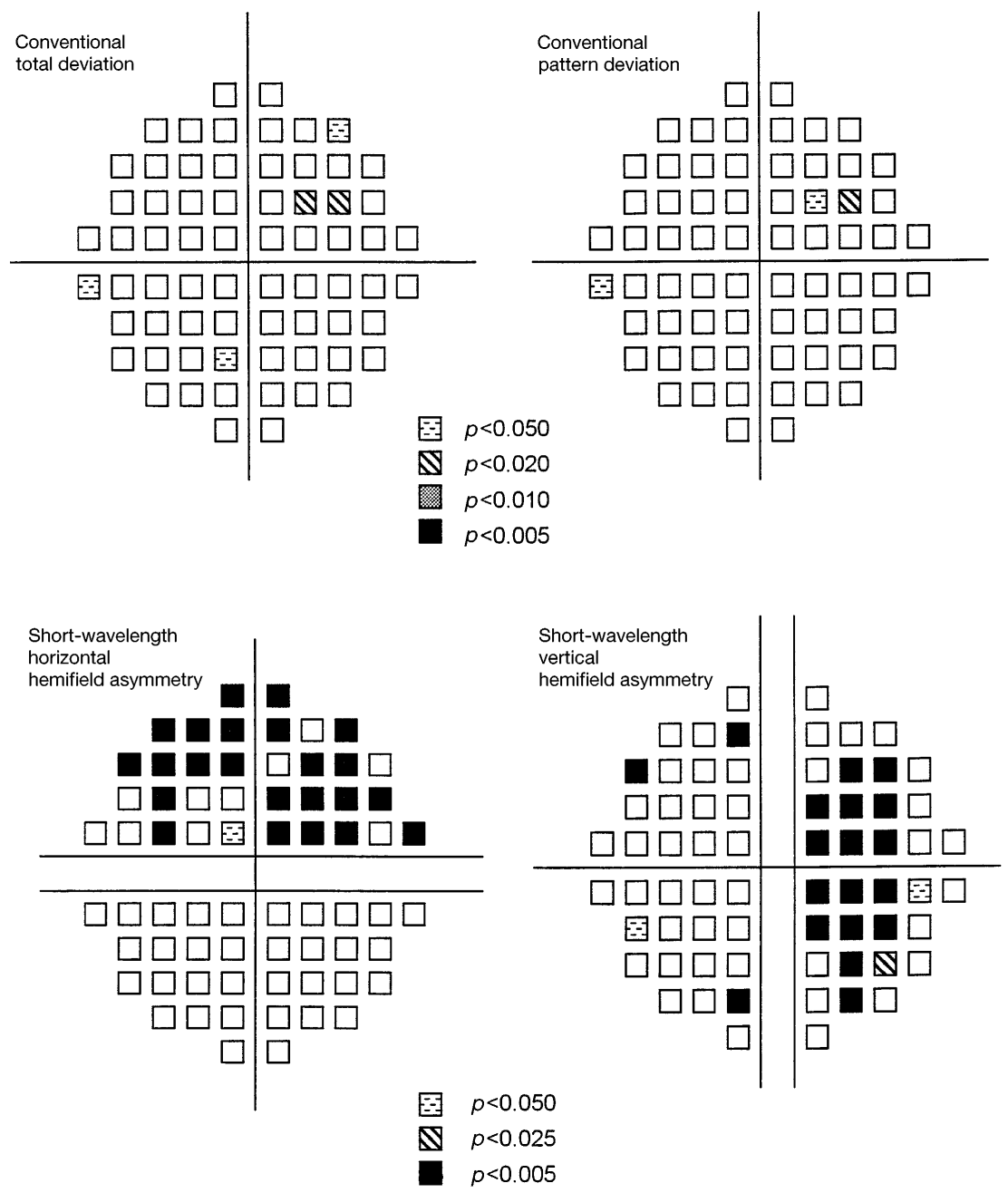

Fig.4. Automated perimetry pointwise probability plots for diabetic patient no. 24 (Left eye, visit 2, short-wavelength perimetry undertaken before conventional perimetry). Top left; Total deviation plot of conventional perimetry. Top right; Pattern deviation plot of conventional perimetry. Bottom left; Horizontal hemifield asymmetry plot of short-wavelength perimetry. Bottom right; Vertical hemifield asymmetry plot of short-wavelength perimetry

zontal hemifield asymmetry plot could result in underestimation of the extent of localised SWS pathway sensitivity loss if the field defect was evenly distributed (and of an equal magnitude of sensitivity loss) across the horizontal midline and located in one hemifield. Indeed, analysis of both the pointwise horizontal and the pointwise vertical hemifield asymmetry plots frequently resulted in a greater extent of localised SWS pathway sensitivity loss than when compared with that of the pointwise horizontal hemifield asymmetry plot alone. Conversely, the extent of localised field loss using short-wavelength perimetry was found to be greater than that suggested by the clinical assessment of DMO in 11 of the 23 patients (Table 2); however, this may be explained by the false-positive flagging of abnormality since the same sensitivity values have been analysed twice to determine the extent of short-wavelength sensitivity loss (i.e. both for the pointwise horizontal and the pointwise vertical hemifield asymmetry plots).

Interpolation procedures for the estimation of perimetric sensitivity have been demonstrated to be as accurate as direct measurements (given the inherent variability) for an inter-stimulus separation of $6^{\circ}$ or less [52]. The accuracy of the interpolation procedure used in this study can be predicted to be high since the interpolation was limited to within $10^{\circ}$ eccentricity of the fovea where the visual field exhibits the greatest symmetry and the within-test measurement variability (i.e. short-term fluctuation) is minimal [53-54]. It is conceivable that a diffuse, or widespread, distribution of DMO may produce a symmetrical loss of short-wavelength sensitivity and consequently may be missed using the pointwise horizontal hemifield asymmetry analysis. However, a diffuse distribution of DMO may not necessarily result in a symmetrical reduction of short-wavelength sensitivity and such gross retinal changes would be obvious on clinical examination. 

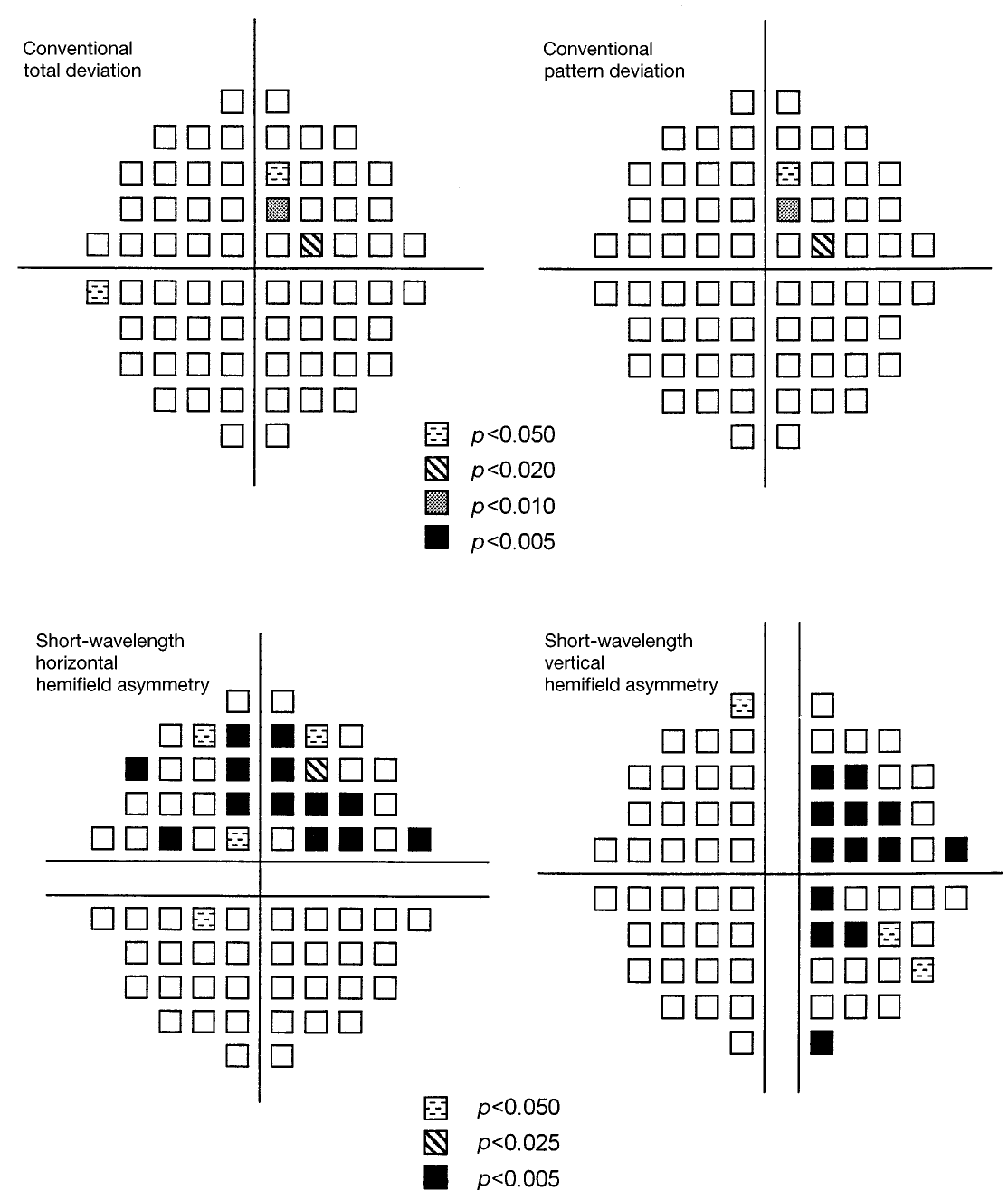

Fig.5. Automated perimetry pointwise probability plots for diabetic patient no. 15 (Left eye, visit 2, short-wavelength perimetry undertaken after conventional perimetry). Top left; Total deviation plot of conventional perimetry. Top right; Pattern deviation plot of conventional perimetry. Bottom left; Horizontal hemifield asymmetry plot of short-wavelength perimetry. Bottom right; Vertical hemifield asymmetry plot of short-wavelength perimetry

The reason for the improved sensitivity in the psychophysical detection of clinically significant DMO offered by short-wavelength perimetry is intriguing. Recent studies have shown that diabetic patients with minimal retinopathy can exhibit selective variations of short-wavelength sensitivity as a result of short and severe manipulation of blood glucose levels [55-56]; this variation of short-wavelength sensitivity is generalised (i.e. rather than localised) and is reversible. The reversible change of shortwavelength sensitivity exhibited by diabetic patients with minimal retinopathy and the SWS pathway localised visual field loss exhibited by patients with DMO may share a common patho-physiological mechanism.
Now, the potential value offered by the pointwise hemifield asymmetry analysis of short-wavelength perimetry (assuming a satisfactory level of specificity) is as a clinical tool for the psychophysical detection of DMO. The technique could be used as a screening procedure for "at risk" diabetic patients and may also be of value for the monitoring of visual function in controlled trials of new treatment regimens. The decision to treat patients with laser photocoagulation, however, will still be based upon morphological criteria until the localised loss of shortwavelength sensitivity can be directly attributed to DMO. A complete understanding of the extraneous factors which impact upon the SWS pathway sensitivity is required before short-wavelength automated perimetry can be used as a reliable indicator of treatment in patients with clinically significant DMO.

Acknowledgements. This work was primarily funded by a postdoctoral fellowship grant from the British Diabetic Association (awarded to Dr Hudson), also by the Manchester Royal Eye Hospital Endowments Fund (awarded to Dr Hudson) and by a research grant from Alcon Laboratories Inc. (awarded to Drs Flanagan and Hudson). We thank Dr Mike Patella of Humphrey Instruments for providing the short-wavelength automated perimetry normal data. 

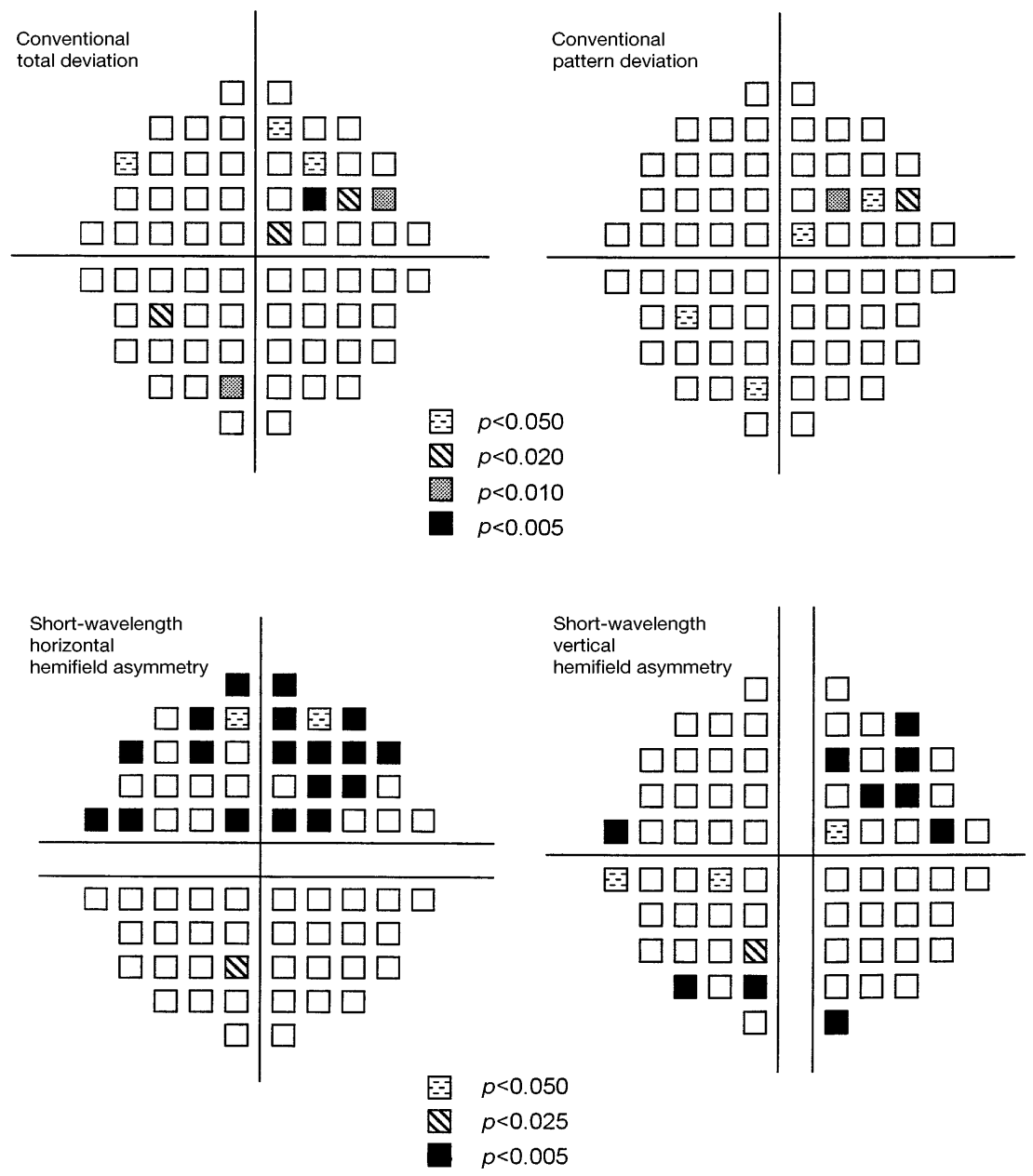

Fig.6. Automated perimetry pointwise probability plots for diabetic patient no. 8 (Right eye, visit 2, short-wavelength perimetry undertaken before conventional perimetry). Top left; Total deviation plot of conventional perimetry. Top right; Pattern deviation plot of conventional perimetry. Bottom left; Horizontal hemifield asymmetry plot of short-wavelength perimetry. Bottom right; Vertical hemifield asymmetry plot of short-wavelength perimetry

\section{References}

1. Hudson C, Wild JM, Archer-Hall JM (1993) Maximizing the dynamic range of the Humphrey Field Analyzer for blue-onyellow perimetry. Ophthalmic Physiol Opt 13: 405-408

2. Flanagan JG, Trope GE, Popick W, Grover A (1991) Perimetric isolation of the SWS cones in OHT and early POAG. In: Mills RP, Heijl A (eds) Perimetry Update 1990/1991. Proceedings of the IXth International Perimetric Society Meeting. Amsterdam, Berkley. Kugler \& Ghedini Publications, Milan, pp 331-337

3. Sample PA, Weinreb RN (1990) Color perimetry for assessment of primary open-angle glaucoma. Invest Ophthalmol Vis Sci 31: 1869-1875

4. Sample PA, Weinreb RN (1992) Progressive color visual fields in glaucoma. Invest Ophthalmol Vis Sci 33: 2068-2071

5. Sample PA, Taylor JDN, Martinez GA, Lusky M, Weinreb RN (1993) Short-wavelength color visual fields in glaucoma suspects at risk. Am J Ophthalmol 115: 225-233
6. Johnson CA, Adams AJ, Casson EJ, Brandt JD (1993) Blueon-yellow perimetry can predict the development of glaucomatous visual field loss. Arch Ophthalmol 111: 645-650

7. Johnson CA, Adams AJ, Casson EJ, Brandt JD (1993) Progression of early glaucomatous visual field loss as detected by blue-on-yellow and standard white-on-white automated perimetry. Arch Ophthalmol 111: 651-656

8. Johnson CA, Brandt JD, Khong AM, Adams AJ (1995) Shortwavelength automated perimetry in low-, medium-, and highrisk ocular hypertensive eyes. Initial baseline results. Arch Ophthalmol 113: 70-76

9. Lewis RA, Johnson CA, Adams AJ (1993) Automated perimetry and short wavelength sensitivity in patients with asymmetric intraocular pressures. Graefes Arch Clin Exp Ophthalmol 231: $274-278$

10. Wild JM, Moss ID, Whitaker D, O'Neill EC (1995) The statistical interpretation of blue-on-yellow visual field loss. Invest Ophthalmol Vis Sci 36: 1398-1410

11. Felius J, de Jong LAM, van den Berg TJTP, Greve EL (1995) Functional characteristics of blue-on-yellow perimetric thresholds in glaucoma. Invest Ophthalmol Vis Sci 36: 1665-1674

12. Zwas F, Weiss H, McKinnon P (1980) Spectral sensitivity measurements in early diabetic retinopathy. Ophthalmic Res 12: 87-96

13. Zisman F, Adams AJ (1982) Spectral sensitivity of cone mechanisms in juvenile diabetics. In: Colour Vision Deficiencies VI. Doc Ophthal Proc Series 33. Verriest G (ed) Dr W Junk, The Hague, pp 127-131

14. Adams AJ, Zisman F, Ai E, Bresnick G (1987) Macular edema reduces B cone sensitivity in diabetics. Applied Optics 26: $1455-1457$ 
15. Adams AJ, Schefrin B, Huie K (1987) New clinical color threshold test for eye disease. American Journal of Optometry and Physiological Optics 64: 29-37

16. Greenstein VC, Hood DC, Ritch R, Steinberger D, Carr RE (1989) S (blue) cone pathway vulnerability in retinitis pigmentosa, diabetes and glaucoma. Invest Ophthalmol Vis Sci 30: 1732-1737

17. Greenstein VC, Hood DC, Carr RE (1989) A comparison of S cone pathway sensitivity loss in patients with diabetes and retinitis pigmentosa. In: Colour Vision Deficiencies IX. Drum B, Verriest G (eds) Kluwer Academic Publishers, Dordrecht, pp 233-241

18. Greenstein VC, Sarter B, Hood D, Noble K, Carr R (1990) Hue discrimination and $\mathrm{S}$ cone pathway sensitivity in early diabetic retinopathy. Invest Ophthalmol Vis Sci 31: 1008-1014

19. Greenstein VC, Shapiro A, Zaidi Q, Hood DC (1992) Psychophysical evidence for post-receptoral sensitivity loss in diabetics. Invest Ophthalmol Vis Sci 33: 2781-2790

20. Adams AJ (1982) Chromatic and luminosity processing in retinal disease. American Journal of Optometry and Physiological Optics 59: 954-960

21. Lutze M, Bresnick GH (1994) Lens-corrected visual field sensitivity and diabetes. Invest Ophthalmol Vis Sci 35: 649-655

22. Sample PA, Esterson FD, Weinreb RN, Boynton RM (1988) The ageing lens: in vivo assessment of light absorption in $84 \mathrm{hu}-$ man eyes. Invest Ophthalmol Vis Sci 29: 1306-1311

23. Sample PA, Esterson FD, Weinreb RN (1989) A practical method for obtaining an index of lens density with an automated perimeter. Invest Ophhalmol Vis Sci 30: 786-787

24. Moss ID, Wild JM, Whitaker DJ (1995) The influence of cataract on blue-on-yellow perimetry. Invest Ophthalmol Vis Sci 36: $764-773$

25. Wild JM, Hudson C (1995) The attenuation of blue-on-yellow perimetry by the macular pigment. Ophthalmology 102: 911-917

26. Hudson C, Wild JM (1993) The influence of pre-receptoral absorption on blue/yellow automated perimetry. In: Perimetry Update 1992-93, Proceedings of the Xth International Perimetric Society Meeting. Mills RP (ed) Kugler Publications, New York, Amsterdam, pp 451-457

27. Sample PA, Martinez GA, Weinreb RN (1993) Color perimetry in glaucoma eyes without correction for lens density. Invest Ophthalmol Vis Sci [suppl]34: 1268

28. Early Treatment Diabetic Retinopathy Study Research group (1987) Treatment techniques and clinical guidelines for photocoagulation of diabetic macular edema. ETDRS Report Number 2. Ophthalmology 94: 761-774

29. Chylack LT, Wolfe JK, Singer DM et al. (1993) The lens opacities classification system III. Arch Ophthalmol 111: 831-836

30. Heijl A, Lingren G, Olsson J (1987) A package for the statistical analysis of visual fields. In: Seventh International Visual Field Symposium. Doc Ophthalmol Proc Ser 49. Greve EL, Heijl A (eds) Martinus Nijhoff/Dr W Junk, Dordrecht, pp 153-168

31. Haley MJ (1987) The Field Analyzer Primer (2nd ed) San Leandro, California, pp 23-25

32. Sample PA, Johnson CA, Haegerstrom-Portnoy G, Adams AJ (1996) Optimum parameters for short-wavelength automated perimetry. Journal of Glaucoma 5: 375-383

33. Bron AJ, Sparrow J, Brown NAP, Harding JJ, Blakytny R (1993) The lens in diabetes. Eye 7: 260-275

34. Hudson C, Wild JM, O'Neill EC (1994) Fatigue effects during a single session of automated static threshold perimetry. Invest Ophthalmol Vis Sci 35: 268-280

35. Heijl A, Lindgren G, Olsson (1989) The effect of perimetric experience in normal subjects. Arch Ophthalmol 107: 81-86
36. Heijl A, Krakau CET (1975) An automatic static perimeter, design and pilot study. Acta Ophthalmol 53: 293-310

37. Heijl A, Asman P (1989) A clinical study of perimetric probability maps. Arch Ophthalmol 107: 199-203

38. Anderson DR (1992) In: Automated Static Perimetry. Kist K(ed) Mosby Year Book Inc. St Louis, pp 80-83

39. Lutze M, Bresnick GH (1991) Lenses of diabetic patients "yellow" at an accelerated rate similar to older normals. Invest Ophthalmol Vis Sci 32: 194-199

40. Klein R, Klein BEK, Moss SE, Davis MD, De Mets DL (1984) The Wisconsin epidemiologic study of diabetic retinopathy. IV. Diabetic macular edema. Ophthalmology 91: 1464-1474

41. Klein R, Moss SE, Klein BEK, Davis MD, De Mets DL (1989) The Wisconsin epidemiologic study of diabetic retinopathy. IX. The incidence of macular oedema. Ophthalmology 96: 1501-1510

42. Early Treatment Diabetic Retinopathy Study Research Group (1985) Photocoagulation for diabetic macular edema. ETDRS Report Number 1. Arch Ophthalmol 103: 1796-1806

43. Early Treatment Diabetic Retinopathy Study Research Group (1991) Early photocoagulation for diabetic retinopathy. ETDRS Report Number 9. Ophthalmology 98: 766-785

44. Davies EG, Petty RG, Kohner EM (1989) Long term effectiveness of photocoagulation for diabetic maculopathy. Eye 3: 764-767

45. Patz A, Smith RE (1991) The ETDRS and Diabetes 2000. Guest Editorial. Ophthalmology 98: 739-740

46. Early Treatment Diabetic Retinopathy Study Research Group (1991) Grading diabetic retinopathy from stereoscopic color fundus photographs. An extension of the modified Airlie House classification. Ophthalmology 98: 786-806

47. Kinyoun J, Barton F, Fisher M, Hubbard L, Aiello L, Ferris F and the EDTRS (1989) Detection of diabetic macular edema. Ophthalmoscopy versus photography. ETDRS report number 5. Ophthalmology 96: 746-751

48. Ferris FL, Patz A (1984) Macular edema. A complication of diabetic retinopathy. Surv Ophthalmol 28: 452-461

49. Bresnick GH (1986) Diabetic macular edema. Ophthalmology 93: 989-997

50. Lyle WM (1974). Drugs and conditions that may affect colour vision. Part 1 - drugs and chemicals. Journal of the American Optometric Society Association. 45: 47-60

51. Heijl A, Lindgren G, Olsson J, Asman P (1989) Visual field interpretation with empiric probability maps. Arch Ophthalmol 107: 204-208

52. Fankhauser F, Bebié H (1979) Threshold fluctuations, interpolations and spatial resolution in perimetry. In Third International Visual Field Symposium. Doc Ophthalmol Proc Ser 19. Greve EL (ed) Dr W Junk, The Hague, pp 295-309

53. Flammer J, Drance SM, Fankhauser F, Augustiny L (1984) Differential light threshold in automated static perimetry. Factors influencing short-term fluctuation. Arch Ophthalmol 102: 876-879

54. Heijl A, Lindgren G, Olsson J (1987) Normal variability of static perimetric threshold values across the central visual field. Arch Ophthalmol 105: 1544-1549

55. Volbrecht VJ, Schneck ME, Adams AJ, Linfoot JA, Ai E (1994) Diabetic short-wavelength sensitivity: Variations with induced changes in blood glucose level. Invest Ophthalmol Vis Sci 35: 1243-1246

56. Schneck ME, Fortune B, Switkes E, Crognale M, Adams AJ (1997) Acute effects of blood glucose on chromatic visually evoked potentials in persons with diabetes and in normal persons. Invest Ophthalmol Vis Sci 38: $800 — 810$ 